\title{
The Effect of Porosity of Submerged and Emerged Breakwater on Wave Transmission
}

\author{
Md. Ataur Rahman and Aysha Akter
}

\begin{abstract}
Porous breakwaters offer an alternative to conventional solid breakwater to create a tranquil water basin for the berthing of vessels by dissipate the energy of incoming waves. The efficiency of the porous breakwaters is governed by their porosity and their depth of submergence. In this study, experimental investigation has been carried out in a two-dimensional wave flume to investigate the effect of porosity on submerged and emerged porous breakwaters under various wave conditions. At $50 \mathrm{~cm}$ still water depth, interactions between regular waves (wave period, $T=1.5 \mathrm{sec}, 1.6 \mathrm{sec}, 1.8 \mathrm{sec}$ and $2.0 \mathrm{sec}$ ) and the fixed vertical porous breakwater of three different porosity $(n=0.45,0.51$ and 0.7$)$ having three different structure heights $\left(h_{b}=40 \mathrm{~cm}, 50 \mathrm{~cm}\right.$ and $\left.60 \mathrm{~cm}\right)$ have been studied experimentally. Experimental results reveal that, minimum transmission co-efficient $\left(K_{t}=0.261\right)$ is obtained for breakwater with lowest porosity $(n=0.45)$ and with emerged condition (when $h_{b} / h=1.2$ ) for short wave, i.e. when $T=1.5 \mathrm{sec}$. Minimum reflection co-efficient $\left(K_{r}=0.089\right)$ is obtained for breakwater with highest porosity $(n=0.7)$ and with minimum submerged $\left(h_{b} / h=0.8\right)$ condition. It is noticed that porosity has effect on the wave energy loss co-efficient also.
\end{abstract}

Index Terms-Porosity, relative submergence, relative width, submerged and emerged breakwater.

\section{INTRODUCTION}

Vertical porous breakwater is considered as a good and cost-effective substitute for the conventional type of breakwaters, especially for coastal works where the tranquility requirements are low. This type occupies small zone, not affecting the seabed creatures. The submerged types of this kind permit to exchange the water masses along the beaches, which minimize the pollution aspects. In addition, the landside of the emerged types of this breakwater can be used for berthing purposes. Porous structures protect lee-side wave attack by reflecting and dissipating wave energy through the viscosity-induced resistance in the porous media. Submerged breakwaters, in addition, may trigger the early breaking of incident waves and dissipate most of the energy. This type is able to enhance water circulation and exchange of water between the open sea and sheltered areas. Because of the submergence of the breakwater, its application to protecting coastal areas may attract more

Manuscript received December 4, 2013; revised March 11, 2014. This research has been supported by the Department of Water Resources Engineering, Bangladesh University of Engineering and Technology (BUET). The authors are grateful to this institute.

Md. Ataur Rahman is with the Department of Water Resources Engineering, Bangladesh University of Engineering and Technology (BUET), Dhaka, Bangladesh (e-mail: mataur@wre.buet.ac.bd).

Aysha Akter is with the Department of Civil Engineering, University of Information Technology and Sciences (UITS), Dhaka, Bangladesh (e-mail: aktera73@yahoo.com). attention due to environmental concerns. The functional performance of the porous breakwater is evaluated by examining the wave reflection, transmission and wave energy dissipation caused by this breakwater. The reflected waves and the dissipated wave energy are strongly affected by water depth, wave properties such as period and height, and structure properties. The major structure properties are porosity, size distribution and shape of the components of the porous media, and geometry such as the clearance of the submerged breakwater.

Many experimental and theoretical studies have been done for determining the efficiency of vertical submerged or emerged permeable or impermeable types of breakwaters. Dalrymple et al. examined the reflection and the transmission coefficients from porous structures under oblique wave attack [1]. Abul-Azm analyzed the linear wave potential near submerged thin barriers using the Eigen Function Expansion to determine the breakwater efficiency [2]. Isaacson et al. carried out an experimental investigation on the reflection of obliquely incident waves from a model rubble-mound breakwater of single slice [3]. Heikal and Attar examined the efficiency of an impermeable, vertical thin submerged breakwater sited on sloping impermeable bed experimentally and numerically by using the Eigen Function Expansion method [4]. Twu et al. studied theoretically, using the Eigen Function Expansion method, the problem of wave transmission over a rectangular and vertically stratified with multi-slice porous material [5]. Stamos and Hajj developed a new method to separate incident and reflected wave components [6]. Then the method is applied to perform a parametric study to compare the reflection and transmission characteristics of flexible and rigid breakwaters. Stamos et al. conducted a parametric experimental study to compare the reflection and transmission characteristics of submerged hemi-cylindrical and rectangular rigid and water-filled flexible breakwater models [7]. Ting et al. investigated how the porosity of submerged breakwaters affects non-breaking wave transformations [8]. Eight model geometries each with six different porosities, from 0.421 to 0.912 , were also considered. Sidek and Wahab experimentally investigated the effects of porosity of submerged breakwater on non-breaking wave transformations [9]. A hollow framework-shaped test model was used. Three models each with three different porosities ranging from 0.40 to 0.80 were used in that experiment. Womera investigated the interaction between waves and rectangular submerged impermeable breakwater [10]. A two-dimensional numerical model based on the SOLA-VOF method was proposed. Vahid and Fatemeh developed an experimental solution for evaluation of transmission coefficients of water waves through single perforated sheets and upright perforated wave filters [11]. Wu et al. conducted experimental and numerical interactions 
between a non-breaking solitary wave and a submerged permeable breakwater [12]. They found that the energy reflection coefficients are dominated by porosity values. More specifically, the energy reflection coefficients decrease with increasing the porosity values. From the review of many related published literature in this field, it is acknowledged that more information are needed from both in the laboratory and the field for the efficient application, development and design of promising vertical porous structures as coastal engineering solutions in the field. In this study, experimental investigation has been carried out in a two dimensional wave tank to understand the effect of porosity in vertical thick submerged and emerged porous breakwaters under wave action.

\section{LABORATORY EXPERIMENT}

Experiments were carried out in a two-dimensional wave flume (21.3 meters long, 0.76 meter wide and 0.74 meter deep) at the Hydraulics and River Engineering Laboratory of Bangladesh University of Engineering and Technology. Rectangular shaped vertical porous breakwater was installed at the middle of the flume. Width of the breakwater (along the wave direction) was $100 \mathrm{~cm}$ and length of the breakwater was same as the width of the wave tank $(76 \mathrm{~cm})$. Height of the breakwater was varied as $h_{b}=40 \mathrm{~cm}, 50 \mathrm{~cm}$ and $60 \mathrm{~cm}$. Three different types of materials (c.c. block, stone chips and brick framework) were used to construct the breakwaters of three different types, which made three different structure porosities. To construct the breakwater, at first rectangular framework was made by steel angles of specified dimensions. Then its outer faces are covered by wire mesh, and steel bars (diameter $4 \mathrm{~mm}$ ) were used to hold the wire mesh tightly with the steel angles. After placing the box in the desired position inside the wave flume, it was filled with the c.c block (having dimension of $4 \mathrm{~cm} \times 4 \mathrm{~cm} \times 2 \mathrm{~cm}$ randomly placed) and stone chips separately as shown in Fig. 1(a), (b), which made porosity $(n)$ of the breakwater 0.51 and 0.45 respectively. For making third type breakwater, construction was done by brick framework as shown in Fig. 1(c), which made the structure porosity as $n=0.7$. Still water depth $(h)$ was maintained in the laboratory flume for all experimental runs as $50 \mathrm{~cm}$. Regular waves with four different wave periods $(T=1.5 \mathrm{~s}, 1.6 \mathrm{~s}, 1.8 \mathrm{~s}$ and $2.0 \mathrm{~s})$ were generated from a flap type wave generator installed at the upstream end of the wave flume. To damp the transmitted wave after passing the breakwater a wave absorber was installed at the end of the wave flume. For each type of breakwater, three different heights of breakwater $\left(h_{b}\right)$ as $40 \mathrm{~cm}, 50 \mathrm{~cm}$ and $60 \mathrm{~cm}$ were used, which made relative structure height (relative submergence), $h_{b} / h=0.8$ (submerged), 1.0 (submerged) and 1.2 (emerged). Interaction of regular waves of four different wave periods with the breakwater of three different porosities and each breakwater having three different heights made thirty six laboratory runs. For each experimental run, wave heights were measured at four locations, two were in front of the break water, third one was over the breakwater and the last one was behind the breakwater. The detail of experimental setup is shown in Fig. 2.

The maximum and the minimum wave heights $\left(H_{\max }\right.$ and $\left.H_{\text {min }}\right)$ at the wave generator side (upstream the breakwater) and the transmitted wave heights $\left(H_{t}\right)$ at the wave absorber side (downstream the breakwater) were measured to estimate the reflection and the transmission coefficients $\left(K_{r}\right.$ and $\left.K_{t}\right)$. Incident wave height $\left(H_{i}\right)$ and reflected wave height $\left(H_{r}\right)$ are calculated as $H_{i}=\left(H_{\max }+H_{\min }\right) / 2$ and $H_{r}=\left(H_{\max }-H_{\min }\right) / 2$ respectively, where $H_{\max }=$ maximum wave height measured at antinodes and $H_{\mathrm{min}}=$ minimum wave height measured at nodes. Then reflection coefficient, $K_{r}=H_{r} / H_{i}$ and transmission coefficient, $K_{t}=H_{t} / H_{i}$ are calculated, where $H_{t}=$ Transmitted wave height. The energy loss coefficient, $K_{L}$ can be calculated from the relation (Thornton and Calhoun 1972): $K_{r}^{2}+K_{t}^{2}+K_{L}^{2}=1$. The conventional method as used by Dean and Dalrymple [1991] has been adopted to separate the measured wave train into its incident and reflected wave components. For measuring maximum and minimum wave heights, two wave gauges were placed at fixed distances of $L / 4$ and $L / 2$ from the breakwater, where $L$ is the wave length. At each position (antinode, $L / 4$ and node, $L / 2$ ) data of water surface were collected for one minute duration at five seconds interval. Then maximum or minimum wave heights $\left(H_{\max }\right.$ or $\left.H_{\min }\right)$ in $\mathrm{cm}$ were calculated by taking difference between the maximum and minimum water surface reading at antinode and node respectively.

\section{RESULTS AND DISCUSSIONS}

\section{A. Effect of Relative Submergence $\left(h_{b} / h\right)$ and Relative Breakwater Width $(k \times B)$ on Wave Transmission}

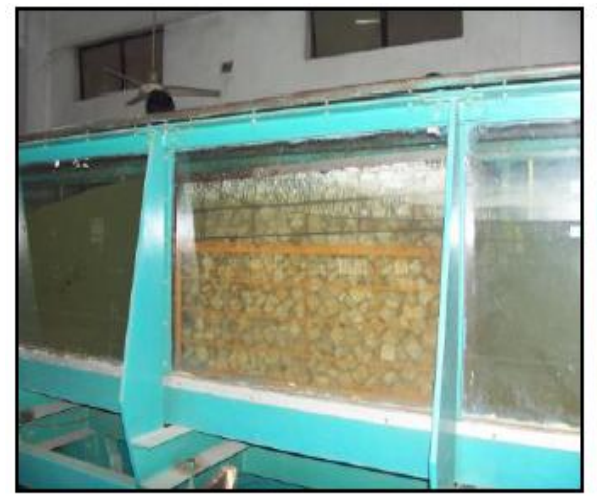

(a)

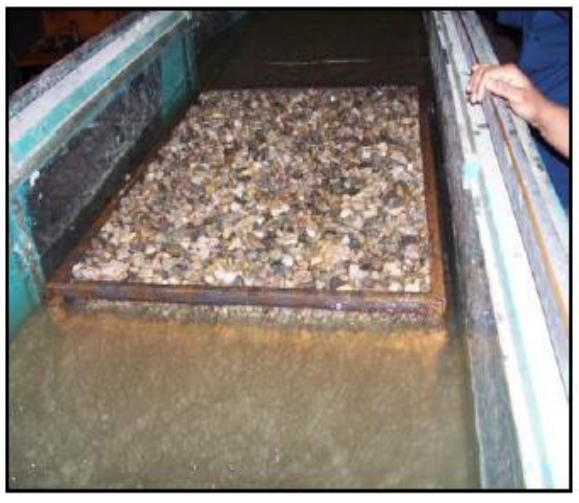

(b)

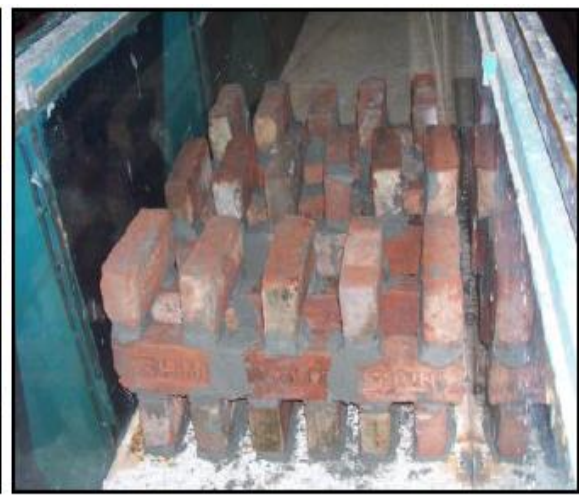

(c)

Fig. 1. Breakwater made of (a) randomly placed c.c. block, (b) stone chips and (c) brick framework. 


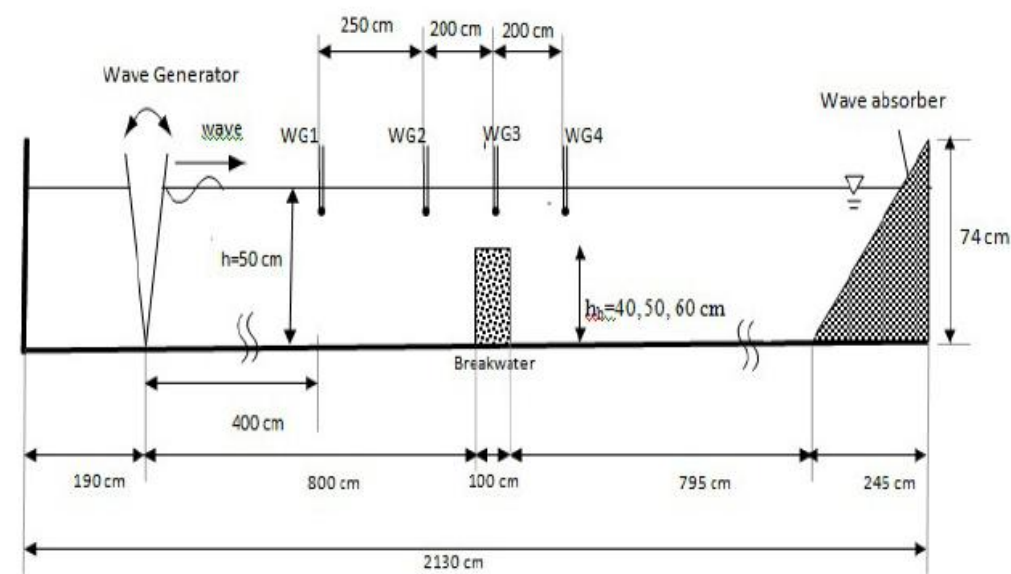

Fig. 2. Experimental set-up for interaction between wave and porous breakwater.

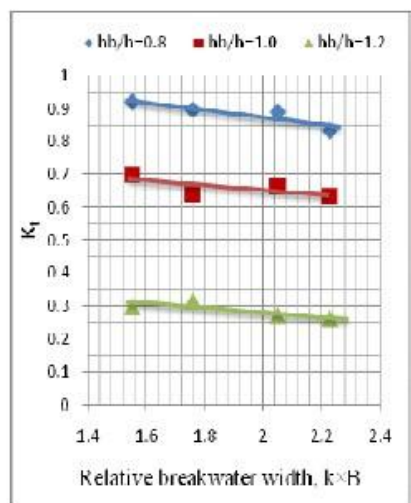

(i)

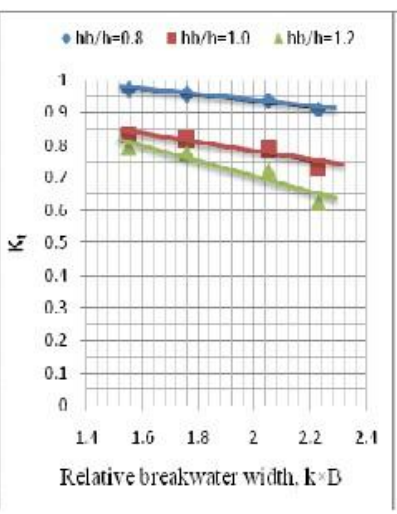

(ii)

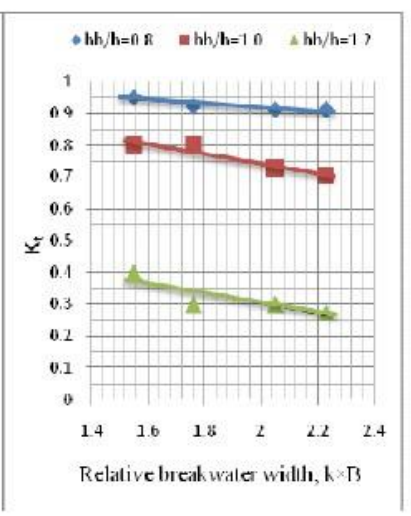

(iii)

Fig. 3. Effect of relative breakwater width on transmission coefficient (Kt) for (i) $n=0.45$, (ii) $n=0.70$, (iii) $n=0.51$.

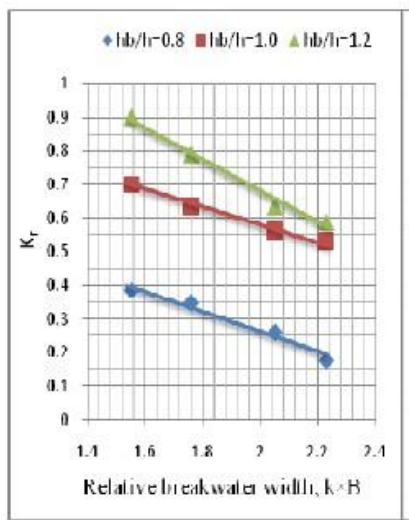

(i)

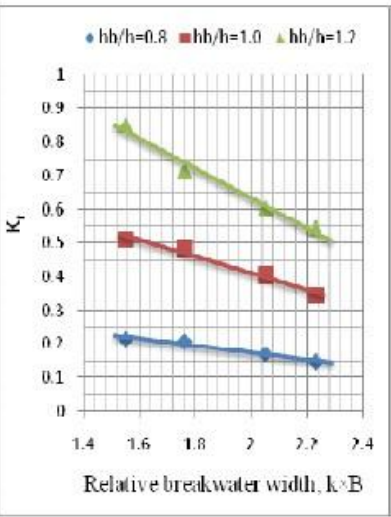

(ii)

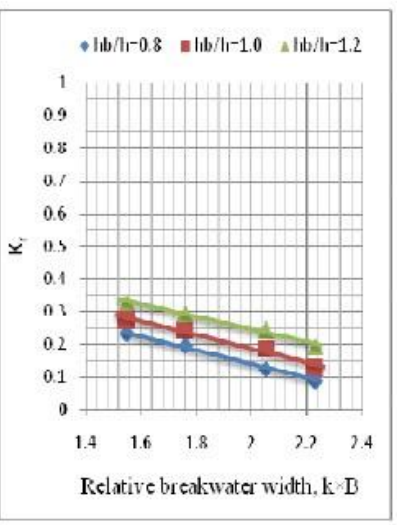

(iii)

Fig. 4. Effect of relative breakwater width on reflection coefficient (Kr) for (i) $n=0.45$, (ii) $n=0.51$, (iii) $n=0.70$.

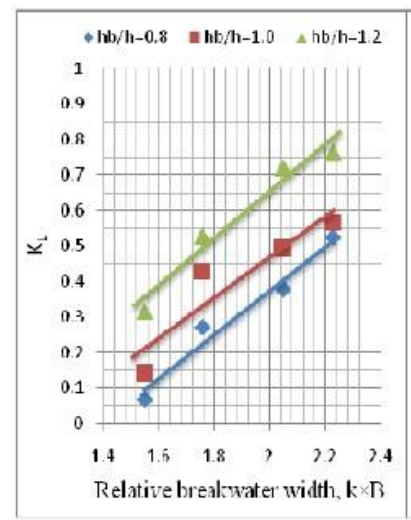

(i)

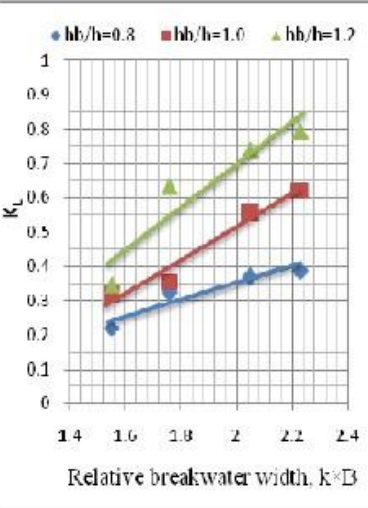

(ii)

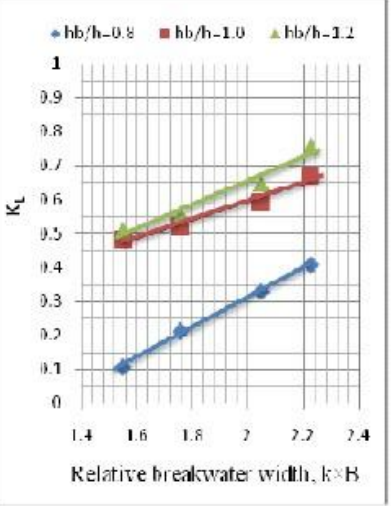

(iii)

Fig. 5. Effect of relative breakwater width on energy loss coefficient ( $K_{L}$ ) for (i) $n=0.45$, (ii) $n=0.5$, (iii) $n=0.70$. 


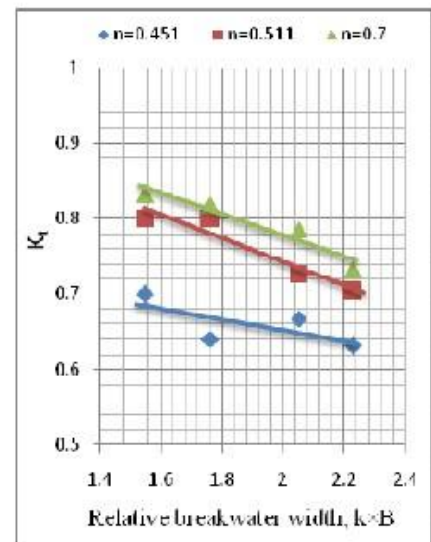

(i)

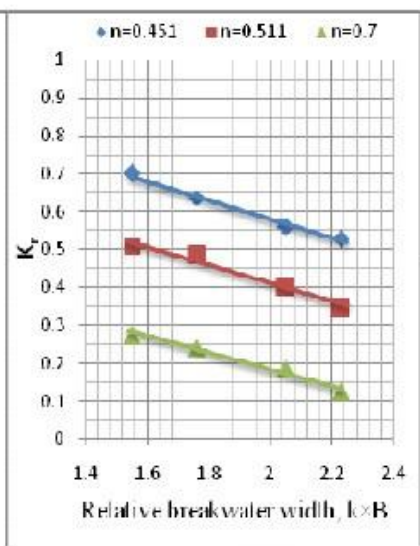

(ii)

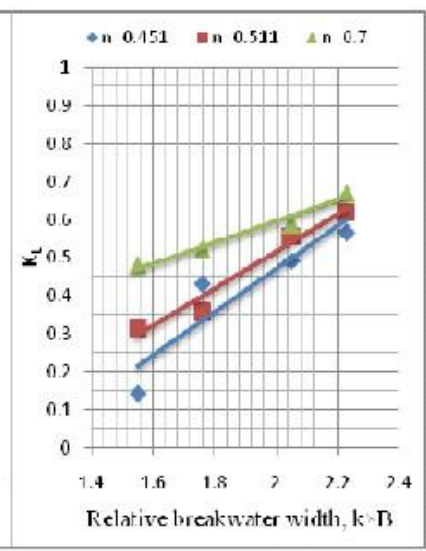

(iii)

Fig. 6. Effect of porosity on (i) $K t$ (ii) $K r$ and (iii) $K L$ for $h b / h=1.0$.

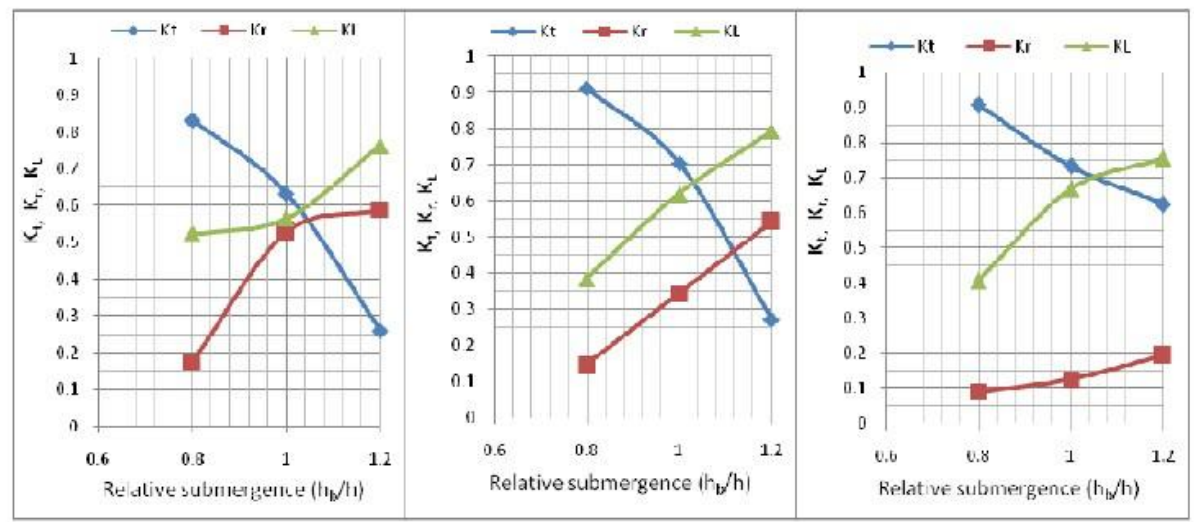

Fig. 7. Variation of $K t, K r$ and $K L$ with relative submergence for (i) $n=0.45, T=1.5 \mathrm{sec}$, (ii)) $n=0.51, T=1.5 \mathrm{sec}$ and (iii) ) $n=0.70, T=1.5 \mathrm{sec}$. (ii)

Fig. 7. Variation of $K t, K r$ and $K L$ with relative submergence for (i) $n=0.45, T=1.5 \mathrm{sec}$, (ii)) $n=0.51, T=1.5 \mathrm{sec}$ and (iii) ) $n=0.70, T=1.5 \mathrm{sec}$.

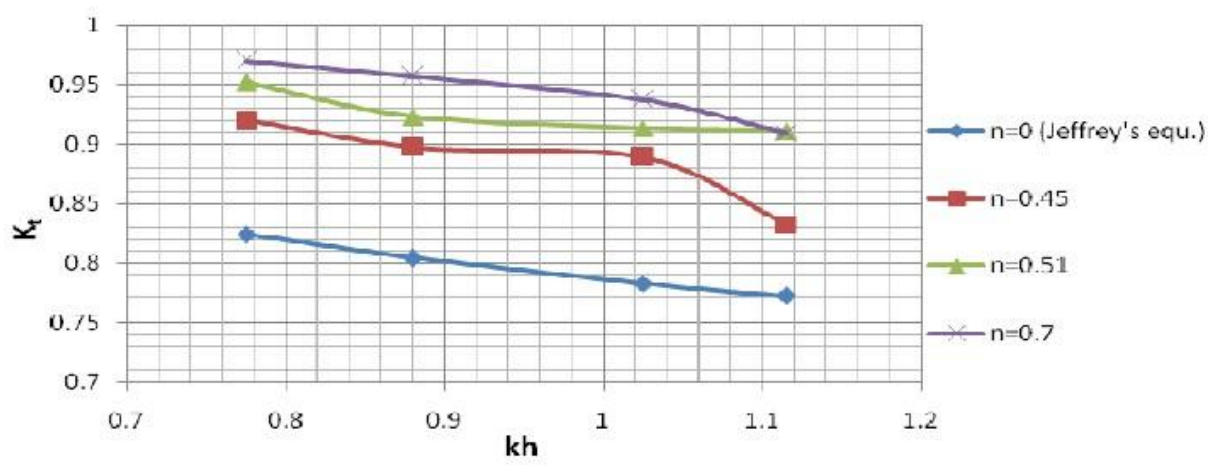

Fig. 8. Effect of breakwater porosity on the transmission coefficient $(K t)$ for $h b / h=0.8$.

Fig. 3(i) to Fig. 3(iii) show the relationship between the transmission coefficient $\left(K_{t}\right)$ and the relative breakwater width $(k \times B)$, where $\mathrm{k}$ is the wave number $(k=2 \pi / L)$. The figures show the results for three relative breakwater heights $\left(h_{b} / h\right)$ as $0.8,1.0$, and 1.2 and also for three different values of the breakwater porosity $(n=0.45,0.70$ and 0.51$)$. It is seen that the transmission coefficient $\left(K_{t}\right)$ decreases as the relative breakwater width $(k \times B)$ increases. This reveals that the breakwater width has influence in damping the transmitted wave. The above mentioned behavior could be attributed to two reasons. First, the increase of the breakwater width causes the increase of the friction between the breakwater surface and the transmitted waves, causing more wave energy loss. Second, as the wave becomes short, the water particle velocity and acceleration suddenly change and the turbulence caused due to this sudden change causes dissipation in the wave energy. In Fig. 3(i), when porosity $n=0.45$, the transmission coefficient $\left(K_{t}\right)$ decreases from 0.92 to 0.833 for $h_{b} / h=0.8$, decreases from 0.7 to 0.632 for $h_{b} / h=1.0$, and decreased from 0.3 to 0.261 for $h_{b} / h=1.2$ with increasing $k \times B$ from 1.55 to 2.23 . When breakwater porosity $\mathrm{n}=0.70$, from Fig. 3(ii), it is seen that for $h_{b} / h=0.8$, the transmission coefficient $\left(K_{t}\right)$ decreases very small amount (from 0.952 to 0.911 ). Whereas, the transmission coefficient $\left(K_{t}\right)$ decreased from 0.8 to 0.705 when $h_{b} / h=1.0$ and decreased from 0.4 to 0.273 when $h_{b} / h=1.2$ for increasing $k \times B$ from 1.55 to 2.23 . When breakwater porosity $n=0.51$, from Fig. 3(iii), it is seen that the transmission coefficient $\left(K_{t}\right)$ have greater value in most of the cases. Due to higher porosity most of the wave energy transmitted directly through the breakwater. When $h_{b} / h=0.8$ the transmission coefficient $\left(K_{t}\right)$ decreases from 0.97 to 0.909 , when $h_{b} / h=1.0$ 
the transmission coefficient $\left(K_{t}\right)$ decreases from 0.833 to 0.733 , when $h_{b} / h=1.2$ the transmission coefficient $\left(K_{t}\right)$ decreases from 0.794 to 0.625 for increasing relative breakwater width $(k \times B)$ from 1.55 to 2.23 .

\section{B. Effect of Relative Submergence $(\mathrm{hb} / \mathrm{h})$ and Relative Breakwater Width $(k \times B)$ on Wave Reflection}

Fig. 4(i) to 4(iii) shows the relationship between the wave reflection coefficient $\left(K_{r}\right)$ and the relative breakwater width $(k \times B)$ for $h_{b} / h=0.8,1.0,1.2$ and $n=0.45,0.51,0.70$. The figure shows that $K_{r}$ decreases as $k \times B$ increases. This may be attributed to the increase of the wave energy loss as the width of the porous media increases. Also, the reflection coefficient $\left(K_{r}\right)$ increases as $h_{b} / h$ increases. Reflection coefficient $\left(K_{r}\right)$ decreases from 0.386 to 0.177 when $h_{b} / h=0.8$, decreases from 0.7 to 0.529 when $h_{b} / h=1$, and decreases from 0.9 to 0.589 when $h_{b} / h=1.2$ for increasing $k \times B$ from 1.55 to 2.23 and for porosity $n=0.45$, which are shown in Fig. 4(i). In Fig. 4(ii), when porosity $n=0.51$, the reflection coefficient $\left(K_{r}\right)$ decreases from 0.214 to 0.147 when $h_{b} / h=0.8$, decreases from 0.51 to 0.345 when $h_{b} / h=1.0$ and decreases from 0.85 to 0.543 when $h_{b} / h=1.2$. When $n=0.70$, the reflection coefficient is very low, as most of the wave energy passes through the breakwater. In Fig. 4(iii), the reflection coefficient $\left(K_{r}\right)$ decreases from 0.234 to 0.089 when $h_{b} / h=0.8$, decreases from 0.274 to 0.125 when $h_{b} / h=1.0$ and decreases from 0.329 to 0.194 when $h_{b} / h=1.2$.

\section{Effect of Relative Submergence $\left(h_{b} / h\right)$ and Relative Breakwater Width on the Wave Energy Loss}

Fig. 5(i) to 5(iii) shows the relationship between the wave energy loss coefficient $\left(K_{L}\right)$ and the relative breakwater width $(k \times B)$ for $h_{b} / h=0.8,1.0,1.2$ and $n=0.45,0.51,0.7$. These figures show that $K_{L}$ increases as $k \times B$ increases. Also the wave energy loss coefficient $\left(K_{L}\right)$ increases as $h_{b} / h$ increases from 0.8 to 1.2 . In Fig. 5(i), when porosity $n=0.45$, the wave energy loss coefficient $\left(K_{L}\right)$ increases from 0.068 to 0.524 for $h_{b} / h=0.8$, increases from 0.141 to 0.567 for $h_{b} / h=1.0$ and increases from 0.316 to 0.765 for $h_{b} / h=1.2$ with increasing $k \times B$ from 1.55 to 2.23 . The wave energy loss coefficient $\left(K_{L}\right)$ increases from 0.219 to 0.385 when $h_{b} / h=0.8$, increases from 0.316 to 0.62 when $h_{b} / h=1.0$ and increases from 0.346 to 0.794 when $h_{b} / h=1.2$ with increasing $k \times B$ from 1.55 to 2.23 and for porosity of breakwater $n=0.51$, as shown in Fig. 5(ii). For $n=0.70$, the wave energy loss coefficient $\left(K_{L}\right)$ increases from 0.105 to 0.407 when $h_{b} / h=0.8$, increases from 0.481 to 0.669 when $h_{b} / h=1.0$ and increases from 0.511 to 0.756 when $h_{b} / h=1.2$ for increasing $k \times B$ from 1.55 to 2.23 , as shown in Fig. 5(iii).

\section{Effect of Breakwater Porosity on the Transmission Co-Efficient $\left(K_{t}\right)$, Reflection Co-Efficient $\left(K_{r}\right)$ and the Wave Energy Loss Co-Efficient $\left(K_{L}\right)$}

Fig. 6(i) to 6(iii) show the variation of the transmission coefficient, reflection co-efficient and the wave energy loss co-efficient for three different porosities $(n=0.45,0.51$ and 0.70 ) of breakwater at relative submergence of $h_{b} / h=1.0$. It is seen that as porosity of breakwater increases, most of the wave energy easily transmits rather dissipating and results higher transmission co-efficient. Reflection co-efficient is seen to increase for less porous breakwater (when $n=0.45$ ).
The wave energy loss co-efficient is less for higher porous breakwater (when $n=0.70$ ). Moreover, the transmission and the reflection co-efficient decreases as the relative breakwater width $(k \times B)$ increases, while the wave energy loss co-efficient takes the opposite trend. For relative submergence $h_{b} / h=1.0$, in Fig. 6(i), it is seen that the transmission co-efficient increases with increasing porosity from $n=0.45$ to $n=0.70$ by about $16 \%$ to $19 \%$ as $k \times B$ increases from 1.55 to 2.23 . For the same case, the reflection co-efficient decreases by $60 \%$ to $76 \%$, as seen in Fig. 6(ii) and wave energy loss co-efficient increases by $1 \%$ to $15 \%$, as seen in Fig. 6(iii).

\section{E. Relation among $K_{t}, K_{r}$ and $K_{L}$ with Respect to Relative Submergence $\left(h_{b} / h\right)$}

Fig. 7 shows the effect of increasing relative submergence $\left(h_{b} / h\right)$ on the transmission co-efficient $\left(K_{t}\right)$, reflection co-efficient $\left(K_{r}\right)$ and the wave energy loss co-efficient $\left(K_{L}\right)$. Here it is observed that with increasing submergence (breakwater height increases from submerged to emerged) the transmission co-efficient decreases, the reflection co-efficient increases, energy loss coefficient increases for any value of breakwater porosity. Fig. 7(i) represents the relation of $K_{t}, K_{r}$ and $K_{L}$ for porosity, $n=0.45$ and wave period, $T=1.5 \mathrm{sec}$. In this case, transmission co-efficient decreases $69 \%$, reflection co-efficient increases $233 \%$ and the wave energy loss co-efficient increases $46 \%$ with increasing submergence from 0.8 to 1.2. Fig. 7(ii) shows the effect of increasing relative submergence $\left(h_{b} / h\right)$ on the transmission co-efficient $\left(K_{t}\right)$, reflection co-efficient $\left(K_{r}\right)$ and the wave energy loss co-efficient $\left(K_{L}\right)$ for porosity $n=0.51$ and wave period, $T=1.5 \mathrm{sec}$. In this case, transmission co-efficient decreases $70 \%$, reflection co-efficient increases $269 \%$ and the wave energy loss co-efficient increases $106 \%$ with increasing submergence from 0.8 to 1.2 . For the breakwater porosity $n=0.7$, transmission co-efficient decreases $31 \%$, reflection co-efficient increases $118 \%$ and the wave energy loss co-efficient increases $86 \%$ with increasing submergence from 0.8 to 1.2, as seen in Fig. 7(iii). But the increasing trends of $K_{r}, K_{L}$ and decreasing trends of $K_{t}$ are seen different for submerged $\left(h_{b} / h \leq 1.0\right)$ and emerged $\left(h_{b} / h>1.0\right)$ condition of the breakwater.

\section{F. Transmission Co-Efficient $\left(K_{t}\right)$ for Various Porosity of Breakwater}

Fig. 8 shows the comparisons of transmission co-efficient for various porosity with respect to $k h$, where $k=$ wave number $(2 \pi / L)$ and $h=$ still water depth. Transmission co-efficient $K_{t}$ for the breakwaters with three different porosities $(n=0.45,0.51$ and 0.7$)$ and for solid or impermeable $(n=0)$ breakwater which was obtained from Jeffreys equation are compared here [13]. The simple empirical equation of transmission co-efficient for rectangular submerged breakwater is as below:

$$
K_{t}=\sqrt{\frac{1}{1+0.25\left[\left(\frac{h}{h-D}\right)^{\frac{1}{2}}-\left(\frac{h-D}{h}\right)^{\frac{1}{2}}\right]^{2} \sin ^{2}\left[\frac{2 B \pi}{T \sqrt{g}}\left(\frac{1}{h-d}\right)\right]}}
$$

where $h$ is the still water depth, $D$ is the breakwater height, $B$ is the breakwater width, $g$ is acceleration of gravity, and $T$ is 
the wave period. From Fig. 8 it is observed that as $k h$ increases, transmission co-efficient $\left(K_{t}\right)$ decreases. The value of transmission co-efficient is greater when porosity, $n=0.7$. When the breakwater is solid having no porosity, then the transmission co-efficient value is low and small amount of wave energy can transmit through the breakwater.

\section{CONCLUSIONS}

In this study the performance of the vertical thick submerged $\left(h_{b} / h=0.8,1.0\right)$ and emerged $\left(h_{b} / h=1.2\right)$ breakwaters with different porosities has been evaluated experimentally under various wave conditions. Thirty six laboratory runs for the wave interaction between wave and porous breakwater in a two dimensional wave tank were conducted. The functional efficiency of porous breakwater is measured by wave reflection, transmission and wave energy loss co-efficient. Experimental data were analysed to calcuate the wave reflection, transmission and wave energy loss co-efficient under various scenarios. Experimental results reveal that, minimum transmission co-efficient $\left(K_{t}=\right.$ $0.261)$ is obtained for breakwater with lowest porosity $(n=$ 0.45 ) and with emerged condition (when $h_{b} / h=1.2$ ) for short wave, i.e. when $T=1.5 \mathrm{sec}$. Minimum reflection co-efficient $\left(K_{r}=0.089\right)$ is obtained for breakwater with highest porosity $(n=0.7)$ and with minimum submerged $\left(h_{b} / h=0.8\right)$ condition. From this study it is revealed that not only the porosity of the breakwater, but also the relative submergence and relative width of the breakwater have strong influences in reflecting wave, transmitting wave and dissipating wave energy. This study may help the coastal engineers for efficient design of the porous submerged or emerged breakwater to be constructed for different purposes.

\section{REFERENCES}

[1] R. A. Dalrymple, M. A. Losada, and P. A. Martin, "Reflection and transmission from porous structures under oblique wave attack," Journal of Fluid Mechanics, vol. 224, pp. 625-644, 1991.

[2] A. G. Abul-Azm, "Wave diffraction through submerged breakwaters," Journal of Waterway, Port, Coastal and Ocean Eng., vol. 119, no. 6, 1993.

[3] M. Isaacson, D. Papps, and E. Mansard, "Oblique reflection characteristics of rubble-mound structures," Journal of Waterways, Port, Coastal, Ocean Eng., ASCE, vol. 122, no. 1, 1996.

[4] E. M. Heikal and A. A. Attar, "Effect of beach slope on the efficiency of submerged breakwaters," in Proc. 2nd Int. Conf., Mansoura Univ., Mansoura, Egypt, 1997.

[5] S. W. Twu, C. C. Liu, and W. H. Hsu, "Wave damping characteristics of deeply submerged breakwaters," Journal of Waterway, Port, Coastal and Ocean Eng., vol. 127, no. 2, 2001.

[6] D. G. Stamos and M. R. Hajj, "Reflection and Transmission of waves over submerged breakwaters," Journal of Engineering Mechanics, vol. 27, pp. 99-105, 2001.
[7] D. G. Stamos, M. R. Hajj, and P. Demetri, "Performance of hemicylindrical and rectangular submerged breakwaters," Journal of Ocean Engineering, vol. 30, iss. 6, 2003.

[8] C. L. Ting, M. C. Lin, and C. Y. Cheng, "Porosity effects on non-breaking surface waves over permeable submerged breakwaters," Journal of Coastal Engineering, vol. 50, iss. 4, 2004.

[9] F. J. Sidek and M. Wahab, "The effects of porosity of submerged breakwater structures on non-breaking wave transformations," Malaysian Journal of Civil Engineering, vol. 19, no.1, pp. 17-25, 2007.

[10] S. A. Womera, "Experimental and numerical investigation on wave interaction with submerged breakwater," M.Sc. Engineering Thesis, Bangladesh University of Engineering and Technology, Dhaka, 2011.

[11] C. Vahid and C. Fatemeh, "Experimental studies of wave transmission through single perforated sheets and upright perforated wave filters," Journal of the Persian Gulf, vol. 2, no. 5, 2011.

[12] Y. Wu, S. Hsiao, and G. Chen, "Solitary wave interaction with a submerged permeable breakwater: Experimental and nnumerical modeling," in Proc. 33rd Conference on Coastal Engineering, Santander, Spain, 2012.

[13] H. Jefferys, "Note on the offshore bar problem and reflection from a bar," Wave Report 3, Grt. Birt. Ministry of Supply, 1944.

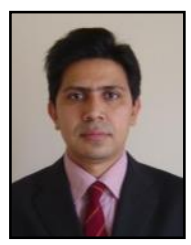

Md. Ataur Rahman was born in Bangladesh in 1973. He received the B.Sc in civil engineering from Bangladesh University of Engineering and Technology (BUET) in 1998, M.Sc in water resources engineering from BUET in 2002 and $\mathrm{PhD}$ in civil engineering from Nagoya University, Japan in 2005. His major research field of study in PhD was coastal engineering.

He joined as a lecturer in the Department of Water Resources Engineering, BUET in 1998. He promoted to an assistant professor in 2002, an associate professor in 2009 and a professor in 2012 in the same Institute.

Prof. Rahman has achieved vast experience in teaching and research in the field of water resources engineering during last fifteen years of his professional career. He has offered around twenty undergraduate courses and six postgraduate courses so far and supervised a number of undergraduate and postgraduate thesis students. His major research area includes coastal engineering, coastal zone management and hydraulics. He has published around twenty-five International Journal and peer reviewed Conference papers. He is Member of Institute of Engineers Bangladesh (IEB), National Oceanographic and Maritime Institute (NOAMI), Bangladesh Water Partnership (BWP) and Universal Association of Civil, Structural and Environmental Engineers (UACSE).

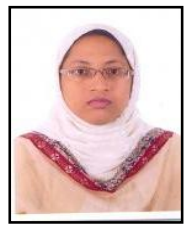

Aysha Akter was born in Dhaka, Bangladesh in 1982 She received the B.Sc in water resources engineering from Bangladesh University of Engineering and Technology (BUET) in 2007 and M.Sc in Water Resources Engineering from BUET in 2013.

She joined as a lecturer in the Department of Civil Engineering, University of Information Technology and Sciences (UITS), Dhaka, Bangladesh in 2012 and continuing there till date. She worked as a teaching assistant in the Department of Water Resources Engineering, BUET during the period of 2008-2009.

Ms. Akter has achieved experience in teaching and research in the field of water resources engineering. She has offered eight undergraduate courses so far and supervised a number of undergraduate thesis students. Her major research area includes coastal engineering and coastal zone management. She is a member of Institute of Engineers Bangladesh (IEB). 